\title{
TFF3 and TFF1 expression levels are elevated in colorectal cancer and promote the malignant behavior of colon cancer by activating the EMT process
}

\author{
AIKEREMU YUSUFU $^{1}$, PAERHATI SHAYIMU ${ }^{1}$, ROUSIDAN TUERDI ${ }^{1}$, \\ CHENG FANG $^{2}$, FEI WANG ${ }^{2}$ and HAIJIANG WANG ${ }^{1}$ \\ ${ }^{1}$ Department of Gastrointestinal Surgery, Affiliated Tumor Hospital, Xin Jiang Medical University, Urumqi, \\ Xinjiang Uygur Autonomous Region 830011; ${ }^{2}$ Department of Gastrointestinal Surgery, \\ Xi Jing Digestive Disease Hospital, Fourth Military Medical University, Xi'an, Shaanxi 710032, P.R. China
}

Received January 31, 2019; Accepted June 27, 2019

DOI: $10.3892 /$ ijo.2019.4854

\begin{abstract}
Reports on the roles of the secreted trefoil factor (TFF) 1 and 3 in colorectal cancer (CRC) and their underlying mechanisms of action in tumorigenesis are not common and are controversial. In the present study, the mRNA expression and promoter methylation of TFF1 and TFF3 in cancer and adjacent normal tissues were investigated, and their association with other clinical factors and patient prognosis were evaluated. Moreover, the association between TFF3 and epithelial-mesenchymal transition (EMT) was explored by overexpressing or inhibiting TFF3 expression. The results revealed that the mRNA level of TFF1 and TFF3 in the cancer tissues was significantly higher than that in the matched adjacent normal tissues $(\mathrm{P}=0.034$ and $\mathrm{P}=0.007$, respectively), and a higher expression of TFF3, but not TFF1, was predominantly associated with clinicopathological factors and a poorer prognosis. No correlation was observed between promoter methylation and the expression of TFF1 or TFF3. The overexpression of TFF3 promoted the proliferation, migration and invasiveness of HT29 cells, and induced an increase in the expression of Twist1, Snail and Vimentin, while causing a decrease in E-cadherin expression. On the contrary, the knockdown of TFF3 resulted in opposite effects in the LoVo cells. On the whole, the findings of this study indicate that TFF3 may be a promising new factor for the estimation of the survival of patients with CRC, and may promote the malignant progression of CRC by activating the EMT process. Therefore, TFF3 may be a future potential therapeutic target for CRC.
\end{abstract}

Correspondence to: Professor Haijiang Wang, Department of Gastrointestinal Surgery, Affiliated Tumor Hospital, Xin Jiang Medical University, 789 East Su Zhou Road, Urumqi, Xinjiang Uygur Autonomous Region 830011, P.R. China

E-mail: wanghaijiang731@126.com

Key words: TFF3, TFF1, colorectal cancer, migration, invasion, epithelial-mesenchymal transition

\section{Introduction}

Colorectal cancer (CRC) is one of the common types of gastrointestinal cancer, with high mortality rates worldwide. It is estimated that $1,361,000$ new cases of CRC were diagnosed in 2012 worldwide, and $18.6 \%(253,000 / 1,361,000)$ of these were diagnosed in China, where CRC has already become the third most common malignancy (1). Metastases, particularly liver metastases, are the main cause of mortality $(2,3)$. The screening of populations at high-risk and the identification of new methods with which to prevent metastasis are the most important aspects for improving the patient survival rate.

The trefoil factors (TFFs) are small secretory peptides with three-loop structures that contain a highly conserved motif of cysteine disulfide bonds that maintain the functional stability of the protein (4-7). Even though TFFs have been shown to protect the gastrointestinal tract against mucosal damage $(8,9)$, there is evidence to indicate a pivotal role for TFFs in the oncogenic transformation, growth and metastasis of human solid tumors (10-12). The TFF family is composed of 3 proteins, TFF1 (pS2), TFF2 (SP) and TFF3 (ITF), and TFF1 is predominantly expressed in the stomach and colon, while TFF3 expression is commonly observed in the intestines (13). In addition, a high expression level of TFF1 has been observed in different tumor tissues (colonic, pancreatic and ovarian) compared with their normal counterparts, and it has also been shown to be associated with cell survival, migration, invasiveness and tumor dissemination (14-16). TFF3 has also been reported to function as an oncogene, promoting cell proliferation and invasion, and increasing the oncogenicity of cells from mammary, gastric and prostate carcinoma tissues (17-19). TFF1 and TFF3 have already been used as markers for the detection of metastatic breast cancer cells $(20,21)$ and have been used as prognostic factors for gastric (22), prostate (23) and rectal cancer (24).

Primarily expressed in the colon, it should be of interest to determine whether TFF1 and TFF3 may be used as effective biomarkers for the prognosis of CRC. It would also be of interest to determine whether a correlation exists between the expression of these two genes and their promoter 
methylation, as well as whether there is a pathway activated by TFF3 that leads to CRC metastasis. To address these questions, in our previous study, the expression of TFF1, TFF3 and Twist1 in different metastatic CRC tissues was evaluated, and different colon cancer cell lines were analyzed to determine the associations between TFF expression and epithelial-mesenchymal transition (EMT), a process required for tumor cell invasion and metastasis in a number of solid tumors. During the EMT process, epithelial cells lose their apico-basal polarity and adherent cell junctions to gain mesenchymal traits, both in morphology and gene expression, becoming more motile and invasive. EMT can be initiated via the expression of various transcription factors, including Twist, Snail, Slug and zinc finger E-box binding homeobox 1 (25-27).

In the present study, the mRNA expression levels and promoter methylation of TFF1 and TFF 3 in cancer and adjacent normal tissues were investigated, and their associations with clinicopathological factors and prognosis were determined. The correlation between TFF promoter methylation and mRNA expression was evaluated and discussed. Lastly, the association between TFF3 and EMT was examined by overexpressing or inhibiting TFF3 expression in vitro.

\section{Materials and methods}

CRC patients and samples. From January, 2011 to January, 2012, 115 patients with CRC who underwent radical resection at the Department of Gastrointestinal Surgery, Tumor Hospital of Xin Jiang Medical University (Ürümqi, China), were enrolled in this study. This study was approved by the Ethics Committee of the Tumor Hospital of Xin Jiang Medical University (approval no. 20110110, 10 January, 2011) and all procedures followed the principles of the Declaration of Helsinki. All subjects provided written informed consent prior to participation. None of the patients had received systemic chemotherapy or radiotherapy prior to surgery. All adjuvant treatments after surgery for all patients were identical. All $\mathrm{CRC}$ tissues and their corresponding adjacent normal tissues were collected during surgery, and immediately snap-frozen in liquid nitrogen. Follow-up visits were performed for survival analysis for up to 75 months after surgery. All clinical features were obtained from medical records.

All cell culture media were purchased from HyClone (GE Healthcare Life Sciences). Three human colon cancer cell (CCC) lines with different invasive potentials (HT29, SW620 and LoVo) and an immortalized human epithelial cell line (HIEC) were donated by the National Laboratory of Xi Jing Digestive Disease Hospital (Fourth Military Medical University, Xi'an). All cell lines were maintained in RPMI-1640 growth medium (Thermo Fisher Scientific, Inc.) supplemented with $10 \%$ heat-inactivated fetal bovine serum, $1 \%$ penicillin and $1 \%$ streptomycin (Thermo Fisher Scientific, Inc.). The HIEC cells were also supplemented with human insulin $(0.1 \mathrm{U} / \mathrm{ml})$.

Total RNA preparation from tissue or cells. Cancer tissues and normal matched normal tissues (which were $15 \mathrm{~cm}$ away from the lesion margin) were obtained during surgery, and stored at $-80^{\circ} \mathrm{C}$ after being snap-frozen. Total RNA was extracted from the tissues and cell lines using TRIzol ${ }^{\circledR}$ reagent (Thermo Fisher
Scientific, Inc.), following the manufacturer's protocol. The concentration and purity of the total RNA were determined by measuring the optical density at 260 and $280 \mathrm{~nm}$. The mRNA extracted from $115 \mathrm{CRC}$ tissue samples and 85 matched normal tissues were included for further analyses.

Reverse transcription-quantitative polymerase chain reaction $(R T-q P C R)$. A total of $1 \mu \mathrm{g}$ total RNA from the tissue or cell lines was used to synthesize cDNA with the help of the PrimeScript RT reagent kit through reverse transcription. Subsequently,qPCR was performedusing BrilliantSYBR-Green QRT-PCR Master Mix as part of a 2-Step kit (Agilent Technologies, Inc.) with the following primers: TFF1 forward, 5'-AATAAGGGCTGCTGTTTCG-3' and reverse, 5'-ACTCCT CTTCTGGAGGGAC-3'; TFF3 forward, 5'-CTGCTGCTTTG ACTCCAGGAT-3' and reverse, 5'-CAGCTGGAGGTGCCTC AGAA-3'; Twist1 forward, 5'-CATGTCCGCGTCCCAC TAG-3' and reverse, 5'-TGTCCATTTTCTCCTTCTCTGG-3'; E-cadherin forward, 5'-GAGTGCCAACTGGACCATTCA GTA-3' and reverse, 5'-AGTCACCCACCTCTAAGGCC ATC-3'; Vimentin forward, 5'-CAGGCAAAGCAGGAGTC CAC-3' and reverse, 5'-GCAGCTTCAACGGCAAAGTTC-3'; Snail forward, 5'-CGCGCTCTTTCCTCGTCA-3' and reverse, 5'-TCCCAGATGAGCATTGGCAG-3; and GAPDH forward, 5'-AGCCTTCTCCATGGTGGTGAA-3' and reverse, 5'-ATC ACCATCTTCCAGGAGCGA-3'. All reactions were performed in triplicate in a $25 \mu \mathrm{l}$ reaction volume. The PCR amplification program consisted of $30 \mathrm{sec}$ of an initial denaturation at $95^{\circ} \mathrm{C}$, followed by 40 cycles of PCR at $95^{\circ} \mathrm{C}$, for $5 \mathrm{sec}$, and then $60^{\circ} \mathrm{C}$ for $30 \mathrm{sec}$. The comparative $\Delta \Delta \mathrm{Cq}$ method was used to determine the relative levels of gene expression (28). Standard curves were drawn, and the relative amount of target gene mRNA was normalized to that of GAPDH. Specificity was verified via melting curve analysis. All experiments were repeated in triplicate.

Sample processing and DNA extraction for promoter methylation. A total of $21 \mathrm{CRC}$ samples and 10 adjacent normal samples were used to evaluate the methylation levels of TFF1 and TFF3 promoter regions. Fresh tumor tissues were snap-frozen in liquid nitrogen instantly after surgical resection and stored at $-80^{\circ} \mathrm{C}$. All tumor specimens were carefully micro-dissected, ensuring that the final tissue samples consisted of at least $85 \%$ tumorous cells. Tissue processing and DNA extraction were performed using the QIAamp DNA Mini kit (Qiagen $\mathrm{GmbH}$ ), according to the manufacturer's protocol.

In vitro transcription and T-cleavage (RNase A digestion) assay. Genomic DNA was treated with bisulfite using an EpiTect Bisulfite kit (Qiagen AB) and then amplified using PCR Accessory Set (Sequenom). In vitro transcription and T-cleavage were performed with Shrimp alkaline phosphatase (Mass CLEAVE kit, Sequenom) before the acquisition of a purified resin-treated product.

Mass spectrometry. The entire RNase A and clean resin treated product were automatically dispensed onto silicon matrix preloaded chips (SpectroCHIP; Sequenom), and the mass spectra were obtained using a Mass ARRAY Compact 
matrix assisted laser desorption ionization-time of flight mass spectrometry (MALDI-TOF-MS) analyzer (Sequenom). The mass spectrometry methylation ratios were generated using EpiTYPER (ver. 4.0; Sequenom).

Western blot analysis. The colon cancer cell lines were harvested separately in ice-cold PBS. Total protein was extracted employing RIPA lysis and extraction buffer (Thermo Fisher Scientific) and quantified by measuring the integrated optical density (IOD) using the BCA Protein Assay kit ( $25 \mu 1$ per lane), and separated by $15 \%$ SDS-PAGE gel electrophoresis, and transferred onto PVDF membranes. The membranes were subsequently blocked with $5 \%(\mathrm{w} / \mathrm{v})$ dried skimmed milk powder in Tris-buffered saline (blocking solution) for $1 \mathrm{~h}$ at room temperature. Subsequently, the membranes were probed with primary antibodies against TFF1 (1:500, ab92377) TFF3 (1:300, ab108599) and Twist1 (1:500, ab50581), E-cadherin (1:500, ab40772), Vimentin (1:500, ab92547), Snail (1:500, ab53519), $\beta$-actin (1:2,500, ab8226) (all from Abcam) in blocking solution overnight at $4^{\circ} \mathrm{C}$. Following a TBS-Tween wash, the membranes were incubated with goat anti-rabbit secondary antibody (HRP; 1:10,000, ab6721) or rabbit anti-goat secondary antibody (HRP; 1:5,000, ab6741) (both from Abcam) in blocking solution for $1 \mathrm{~h}$ at room temperature. Immunoreactive proteins were detected using enhanced chemiluminescence kit (Thermo Scientific Pierce ECL Substrate). The intensity of the bands on western blot was evaluated by Quantity One ${ }^{\circledR} 1$-D analysis software (version 4.62, Bio-Rad).

Plasmid construction and cell transfection. The TFF3 expression plasmid was built by cloning TFF3 cDNA into a pIRES2-enhanced green fluorescent protein vector (no. 6029-1,Clontech). The transfection of TFF3 expression or empty vector plasmids (pIRES2-EGFP) into the HT29 cells was performed using Lipofectamine 3000 transfection reagent (Thermo Fisher Scientific, Inc.), according to the manufacturer's protocol. The cells were incubated at $37^{\circ} \mathrm{C}$ in $5 \% \mathrm{CO}_{2}$ incubator for $48 \mathrm{~h}$, and fluorescence photography following transfection was then carried out to evaluate the efficiency of transfection.

Gene knockdown assay. The short hairpin RNA (shRNA) sequences against TFF3 and control shRNA were purchased from Thermo Fisher Scientific, Inc. LoVo cells were transfected with $30 \mathrm{nM}$ shRNAs using Lipofectamine 3000 transfection reagent (Thermo Fisher Scientific, Inc.), according to the manufacturer's protocol. Following incubation at $37^{\circ} \mathrm{C}$ with $5 \% \mathrm{CO}_{2}$ for $48 \mathrm{~h}$, the knockdown of TFF3 was confirmed by both RT-qPCR and western blot analysis.

Cell proliferation assay. Cell proliferation rates were measured by CCK- 8 cell proliferation assay. The prepared cell suspension (100 $\mu \mathrm{l} /$ well) in a 96 -well plate was pre-incubated at $37^{\circ} \mathrm{C}$ in $5 \% \mathrm{CO}_{2}$ and $10 \mu \mathrm{l}$ of the CCK-8 (Alpha CP8 Cell Proliferation Assay kit,no. A32001-500T, Alpha Applied Bioscience) solution were added to each well, and incubation was maintained in an incubator for 1-4 h before measuring the absorbance at $450 \mathrm{~nm}$ using a microplate reader (Varioskan LUX, Thermo Fisher Scientific).
Cell migration and invasion assays. Scratch-wound healing and Transwell assays were performed to evaluate cell migration and invasion. CCCs were grown to $90 \%$ confluence before an $\sim 0.6 \mathrm{~mm}$ wide wound was created with the help of an insert. The wounds were subsequently imaged at 0,24 and $48 \mathrm{~h}$ to assess the level of motility. The cell migratory ability was quantified by calculating the area between the two leading edges of cells using ImageJ software (version 1.52e, Broken Symmetry Software).

For the Transwell assays, 24-well Transwell units with $8 \mu \mathrm{m}$ pore-size filters (Corning, Inc.) were precoated with $40 \mu \mathrm{l}$ Matrigel (for invasion assay) or without Matrigel (for migration assay). A total of $200 \mu \mathrm{l}$ of a cell suspension containing $5 \times 10^{4}$ cells $/ \mathrm{ml}$ in serum-free medium were inserted into the upper chamber. In the lower chamber, $300 \mu 1$ Dulbecco's modified Eagle's medium containing $20 \%$ fetal calf serum were added. Following a $24-\mathrm{h}$ incubation at $37^{\circ} \mathrm{C}$ with $5 \% \mathrm{CO}_{2}$, the cells in the upper chamber were removed with a cotton swab and the traversed cells in the lower chamber were fixed with $4 \%$ paraformaldehyde, stained with $0.5 \%$ crystal violet (no. 32675, Sigma-Aldrich) at room temperature for $10 \mathrm{~min}$ and counted in 5 randomly chosen fields under a light microscope (SFC-100 Series, Motic Europe).

Ultrastructure observation by transmission electron microscopy (TEM). The cells were collected and fixed using $2.5 \%$ TEM-specific glutaric dialdehyde solution at $48 \mathrm{~h}$ following transfection. The cells were then centrifugated at a speed of $2,504 \mathrm{x} \mathrm{g}$ at room temperature and fixed in $1 \%$ osmium tetroxide at $4^{\circ} \mathrm{C}$ for $15-30 \mathrm{~min}$ before dehydrating in acetone solutions of 50, 70, 90 and $100 \%$. The cells were subsequently embedded in epoxy resin (EPON812), sliced into 50-70 $\mathrm{nm}$ ultrathin sections after being fixed on metal mesh and stained with sodium acetate at room temperature for 5-30 min, and observed under a transmission electron microscope (JEM-ARM200F NEOARM). Moreover, cell morphology was photographed under an optical microscope (SFC-100 Series, Motic Europe) to observe the changes in cell morphology following the overexpression or silencing of TFF3.

Statistical analysis. The continuous data are presented as the means \pm standard deviation, and compared using a unpaired Student's t-test (as comparison of mRNA levels of TFF3 or TFF1) or Mann Whitney U test (due to the unpaired, non-normal distribution of methylation level of TFF3 or TFF1). One way analysis of variance (ANOVA) with an LSD post hoc test was used to compare the group data. The clinicopathological features were analyzed between the high TFF3 and low TFF3 expression groups using a Pearson $\chi^{2}$ test or $\chi^{2}$ test with Yates' correction. Pearson's correlation analysis was performed to evaluate the correlation between relevant factors. The cumulative survival rates were determined using the Kaplan-Meier method and compared with the log-rank test. The Cox proportional hazards test was used for univariate and multivariate survival analysis. All statistical analyses were performed using GraphPad Prism 5 software (GraphPad Software, Inc.) or SPSS 18.0 (SPSS, Inc.). $\mathrm{P}<0.05$ was considered to indicate a statistically significant difference. 

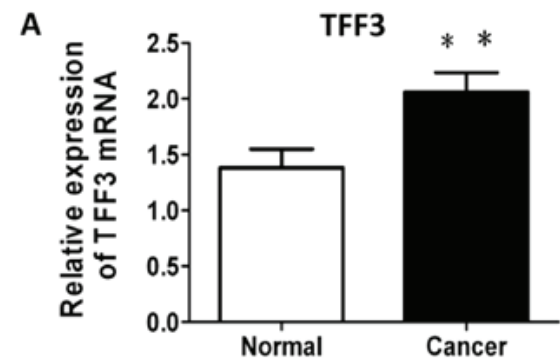

B

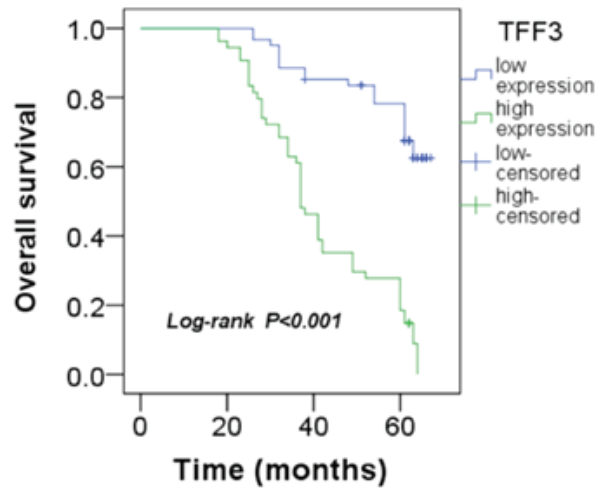

TFF1
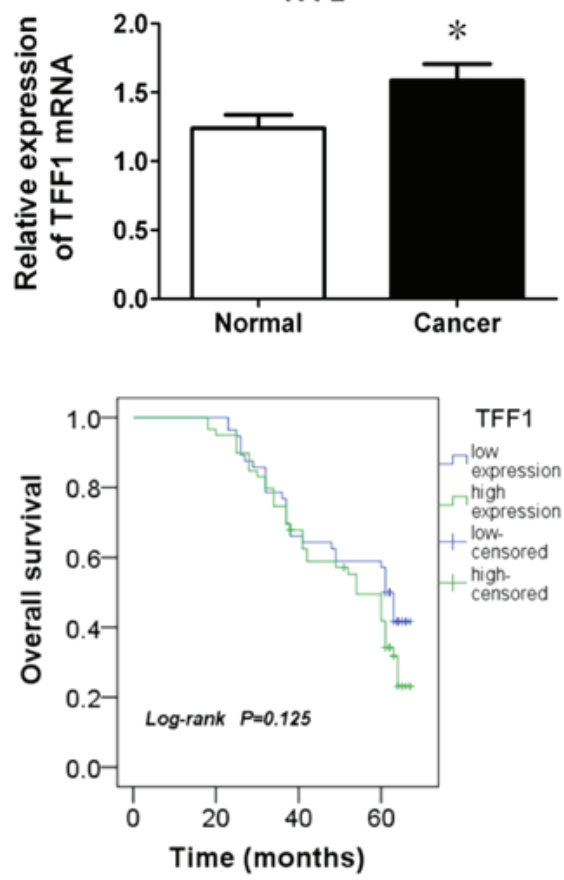

Figure 1. mRNA expression of TFF1 and TFF3 in cancer and normal tissues and the association with survival. (A) mRNA expression of TFF1 or TFF3 in cancer tissues was higher than that in normal tissues $(\mathrm{P}=0.034$ or $\mathrm{P}=0.007)$. (B) Survival analysis revealed that a higher expression of TFF3 was associated with a worse overall survival, while TFF1 expression demonstrated no association with patient survival $(\mathrm{P}<0.001$ and $\mathrm{P}=0.125)$. ${ }^{*} \mathrm{P}<0.05$ and ${ }^{* *} \mathrm{P}<0.01$ vs. normal group. TFF, trefoil factor.

Table I. Comparison of TFF1 and TFF3 mRNA in normal and cancer tissue.

\begin{tabular}{llcr}
\hline & \multicolumn{2}{c}{$\begin{array}{c}\text { Relative expression of mRNA } \\
(\text { means } \pm \text { SD) }\end{array}$} & \\
\cline { 2 - 3 } Gene & Normal $(\mathrm{n}=85)$ & Cancer $(\mathrm{n}=115)$ & P-value \\
\hline TFF1 & $1.228 \pm 0.097$ & $1.635 \pm 0.117$ & 0.034 \\
TFF3 & $1.383 \pm 0.166$ & $2.060 \pm 0.175$ & 0.007
\end{tabular}

A value of $\mathrm{P}<0.05$ was considered to indicate a statistically significant difference (unpaired Student's t-test). TFF, trefoil factor.

\section{Results}

mRNA expression of TFF1 and TFF3 and correlation with clinicopathological factors. The results from the analysis of the mRNA expression of TFF1 or TFF3 in the CRC tissues and matched adjacent normal tissues are presented in Table I and Fig. 1A. The average mRNA levels of TFF1 or TFF3 in the cancer tissue were significantly higher than those in the matched adjacent normal tissue $(\mathrm{P}=0.034$ and $\mathrm{P}=0.007$, respectively). The analysis of correlation between the mRNA expression of TFF1 and TFF3 indicated the existence of a positive association between TFF1 and TFF3 mRNA expression in patients with $\mathrm{CRC}(\mathrm{r}=0.219, \mathrm{P}=0.019$; Table II).

The association between the expression of two TFF genes and the clinicopathological characteristics of the patients with CRC was further analyzed. The higher expression of TFF3 was significantly associated with histological type, invasion
Table II. Correlation between mRNA expression of TFF1 and TFF3 in patients with CRC.

\begin{tabular}{ccccc}
\hline & \multicolumn{2}{c}{ TFF1 } & & \\
\cline { 2 - 3 } Gene & $\begin{array}{c}\text { Low } \\
\mathrm{n}\end{array}$ & $\begin{array}{c}\text { High } \\
\mathrm{n}\end{array}$ & $\mathrm{r}$ & P-value \\
\hline TFF3 & & & & \\
Low & 36 & 25 & 0.219 & $0.019^{\mathrm{a}}$ \\
High & 20 & 34 & & \\
\hline
\end{tabular}

${ }^{\mathrm{a}} \mathrm{P}<0.05$ was considered to indicate a statistically significant difference (Pearson's correlation test).

depth (T), lymph node number (N), metastasis at diagnosis (M), overall TNM staging and recurrence or metastasis following treatment. Only the circumferential resection margin (CRM), metastasis at diagnosis and TNM staging were associated with a higher expression of TFF1 (Table III).

TFF3 expression is visibly increased in CRC tissue and is associated with a poor prognosis. The 115 patients with CRC were divided into the high or low expression group according to the X-tile algorithm (29), which generated optimal cut-off values for the TFF3 and TFF1 mRNA levels in the CRC samples. The 1-,3-and 5-year survival rates of the patients in the high TFF3 expression group were 91, 55.9 and $21.1 \%$, respectively, and in the low TFF3 in the low TFF3 group, they were $100,85.2$ and $53.9 \%$, respectively (data not shown). Survival analysis revealed that a higher expression of TFF3 
Table III. Association between TFF1 or TFF3 mRNA expression and patient clinicopathological factors.

\begin{tabular}{|c|c|c|c|c|c|c|}
\hline \multirow[b]{2}{*}{$\begin{array}{l}\text { Clinicopathological factors } \\
(n=115)\end{array}$} & \multicolumn{2}{|c|}{ TFF1 } & \multirow[b]{2}{*}{ P-value } & \multicolumn{2}{|c|}{ TFF3 } & \multirow[b]{2}{*}{ P-value } \\
\hline & $\begin{array}{c}\text { Low } \\
\mathrm{n}\end{array}$ & $\begin{array}{l}\text { High } \\
\mathrm{n}\end{array}$ & & $\begin{array}{c}\text { Low } \\
\mathrm{n}\end{array}$ & $\begin{array}{l}\text { High } \\
\mathrm{n}\end{array}$ & \\
\hline Age (years) & & & 0.710 & & & 0.266 \\
\hline$\leq 60$ & 26 & 25 & & 24 & 27 & \\
\hline$>60$ & 30 & 34 & & 37 & 27 & \\
\hline Sex & & & 0.519 & & & 0.560 \\
\hline Male & 33 & 34 & & 34 & 33 & \\
\hline Female & 23 & 25 & & 27 & 21 & \\
\hline Race & & & 0.874 & & & 0.668 \\
\hline Han & 42 & 45 & & 45 & 42 & \\
\hline Uyghur & 14 & 14 & & 16 & 12 & \\
\hline Blood type & & & 0.869 & & & 0.135 \\
\hline $\mathrm{A}$ & 15 & 18 & & 17 & 16 & \\
\hline B & 22 & 25 & & 30 & 17 & \\
\hline $\mathrm{AB}$ & 3 & 2 & & 3 & 2 & \\
\hline $\mathrm{O}$ & 16 & 14 & & 11 & 19 & \\
\hline Histological type & & & 0.348 & & & $0.006^{\mathrm{a}}$ \\
\hline Adenocarcinoma & 47 & 53 & & 58 & 42 & \\
\hline $\begin{array}{l}\text { Mucinous or signet } \\
\text { ring cell }\end{array}$ & 9 & 6 & & 3 & 12 & \\
\hline Differentiation & & & 0.111 & & & 0.167 \\
\hline Well & 13 & 20 & & 15 & 18 & \\
\hline Moderate & 29 & 32 & & 35 & 26 & \\
\hline Poor & 9 & 2 & & 8 & 3 & \\
\hline None & 5 & 5 & & 3 & 7 & \\
\hline Location & & & 0.549 & & & 0.335 \\
\hline Colon & 22 & 20 & & 25 & 17 & \\
\hline Rectum & 34 & 39 & & 36 & 37 & \\
\hline Tumor size & & & 0.140 & & & 0.565 \\
\hline$\leq 5 \mathrm{~cm}$ & 37 & 31 & & 36 & 32 & \\
\hline$>5 \mathrm{~cm}$ & 19 & 28 & & 25 & 22 & \\
\hline Gross type & & & 0.414 & & & 0.670 \\
\hline Massive & 24 & 22 & & 24 & 22 & \\
\hline Ulcerous & 29 & 36 & & 34 & 31 & \\
\hline Infiltrative & 3 & 1 & & 3 & 1 & \\
\hline CRM & & & $0.044^{\mathrm{a}}$ & & & 0.084 \\
\hline Negative & 53 & 48 & & 57 & 44 & \\
\hline Positive & 3 & 11 & & 4 & 10 & \\
\hline Vascular invasion & & & 0.178 & & & 0.075 \\
\hline Negative & 49 & 46 & & 54 & 41 & \\
\hline Positive & 7 & 13 & & 7 & 13 & \\
\hline Perineural invasion & & & 0.095 & & & 0.436 \\
\hline Negative & 54 & 51 & & 3 & 3 & \\
\hline Positive & 2 & 8 & & 26 & 30 & \\
\hline Invasion depth & & & 0.428 & & & $0.001^{\mathrm{a}}$ \\
\hline $\mathrm{T} 1+2$ & 11 & 10 & & 13 & 8 & \\
\hline $\mathrm{T} 3$ & 26 & 22 & & 16 & 32 & \\
\hline $\mathrm{T} 4$ & 19 & 27 & & 32 & 14 & \\
\hline Lymph node number & & & 0.783 & & & $0.001^{\mathrm{a}}$ \\
\hline None & 11 & 9 & & 15 & 5 & \\
\hline$<4$ & 24 & 25 & & 31 & 18 & \\
\hline$\geq 4$ & 21 & 25 & & 15 & 31 & \\
\hline
\end{tabular}


Table III. Continued.

\begin{tabular}{|c|c|c|c|c|c|c|}
\hline \multirow[b]{2}{*}{$\begin{array}{l}\text { Clinicopathological factors } \\
(\mathrm{n}=115)\end{array}$} & \multicolumn{2}{|c|}{ TFF1 } & \multirow[b]{2}{*}{ P-value } & \multicolumn{2}{|c|}{ TFF3 } & \multirow[b]{2}{*}{ P-value } \\
\hline & $\begin{array}{c}\text { Low } \\
\mathrm{n}\end{array}$ & $\begin{array}{l}\text { High } \\
\mathrm{n}\end{array}$ & & $\begin{array}{c}\text { Low } \\
\mathrm{n}\end{array}$ & $\begin{array}{l}\text { High } \\
\mathrm{n}\end{array}$ & \\
\hline Metastasis at diagnosis & & & $0.001^{\mathrm{a}}$ & & & $0.027^{\mathrm{a}}$ \\
\hline No & 51 & 37 & & 52 & 36 & \\
\hline Yes & 5 & 22 & & 9 & 18 & \\
\hline TNM staging & & & $0.020^{\mathrm{a}}$ & & & $0.017^{\mathrm{a}}$ \\
\hline $\mathrm{I}+\mathrm{II}$ & 11 & 9 & & 15 & 5 & \\
\hline III & 40 & 28 & & 37 & 31 & \\
\hline IV & 5 & 22 & & 9 & 18 & \\
\hline $\begin{array}{l}\text { Recurrence or metastasis } \\
\text { after surgery }\end{array}$ & & & 0.192 & & & $0.001^{\mathrm{a}}$ \\
\hline No & 33 & 27 & & 47 & 13 & \\
\hline Yes & 23 & 32 & & 14 & 41 & \\
\hline
\end{tabular}

${ }^{\mathrm{a}} \mathrm{P}<0.05$ was considered to indicate a statistically significant difference (Pearson's Chi-square test or Chi-square with Yates' correction). CRM, circumferential resection margin; TFF, trefoil factor.

Table IV. Significant predictive factors (univariate and multivariate) for overall survival in Cox proportional-hazard analysis.

\begin{tabular}{|c|c|c|c|c|}
\hline Prognostic factor & Univariate HR (95\% CI) & P-value & Multivariate HR (95\% CI) & P-value \\
\hline Age & $0.723(0.454-1.151)$ & 0.171 & $1.436(0.600-3.435)$ & 0.416 \\
\hline Sex & $1.147(0.715-1.838)$ & 0.570 & $1.414(0.566-3.535)$ & 0.458 \\
\hline Race & $1.182(0.704-1.984)$ & 0.527 & $1.580(0.624-4.000)$ & 0.334 \\
\hline Blood type & $0.910(0.686-1.208)$ & 0.514 & $1.518(0.887-2.597)$ & 0.128 \\
\hline Location & $0.782(0.473-1.292)$ & 0.338 & $0.730(0.297-1.793)$ & 0.493 \\
\hline Histological type & $0.974(0.484-1.960)$ & 0.942 & $0.380(0.080-1.809)$ & 0.224 \\
\hline Differentiation & $0.753(0.561-1.010)$ & 0.059 & $0.717(0.415-1.239)$ & 0.234 \\
\hline Gross type & $1.080(0.718-1.626)$ & 0.712 & $1.327(0.590-2.980)$ & 0.494 \\
\hline CRM & $2.259(1.198-4.260)$ & $0.012^{\mathrm{a}}$ & $2.997(0.412-21.822)$ & 0.278 \\
\hline Perineural invasion & $1.869(0.891-3.918)$ & 0.098 & $0.196(0.023-1.690)$ & 0.138 \\
\hline Vascular invasion & $2.269(1.323-3.890)$ & $0.003^{\mathrm{a}}$ & $1.210(0.317-4.612)$ & 0.780 \\
\hline $\mathrm{T}$ & $0.987(0.722-1.350)$ & 0.936 & $3.100(1.159-8.292)$ & $0.024^{\mathrm{a}}$ \\
\hline $\mathrm{N}$ & 1.476 ( $1.080-2.019)$ & $0.015^{\mathrm{a}}$ & $1.125(0.480-2.639)$ & 0.786 \\
\hline M & $2.103(1.264-3.496)$ & $0.004^{\mathrm{a}}$ & $0.048(0.004-0.635)$ & $0.021^{\mathrm{a}}$ \\
\hline Staging & $1.979(1.380-2.840)$ & $0.001^{\mathrm{a}}$ & $8.141(1.076-61.563)$ & $0.042^{\mathrm{a}}$ \\
\hline Recurrence or metastasis & $6.844(4.018-11.656)$ & $0.001^{\mathrm{a}}$ & $12.048(3.310-3.852)$ & $0.001^{\mathrm{a}}$ \\
\hline TFF1 & $1.427(0.894-2.277)$ & 0.137 & $1.311(0.392-4.381)$ & 0.660 \\
\hline TFF3 & $5.645(3.342-9.533)$ & $0.000^{\mathrm{a}}$ & $3.432(1.056-11.155)$ & $0.040^{\mathrm{a}}$ \\
\hline Tumor size & $0.975(0.611-1.557)$ & 0.917 & $0.321(0.107-0.964)$ & $0.043^{\mathrm{a}}$ \\
\hline
\end{tabular}

${ }^{\mathrm{a}}<0.05$ was considered to indicate a statistically significant difference.

was associated with a worse overall survival, while TFF1 expression demonstrated no association with patient survival $(\mathrm{P}<0.001$ and $\mathrm{P}=0.125$, respectively; Fig. 1B). Furthermore, predictive factors of patient survival were calculated using a Cox proportional-hazard model. CRM, vascular invasion, lymph node number $(\mathrm{N})$, metastasis at diagnosis (M),
TNM staging, recurrence or metastasis following treatment and TFF3 were associated with patient survival by univariate analysis, while invasion depth (T), metastasis at diagnosis (M), TNM staging, recurrence or metastasis following treatment, tumor size and TFF3 were found to be the predictive factors of patient survival by multivariate analysis (Table IV). 
A $\quad 0 \% 0000000000100 \%$ Not enatrzed

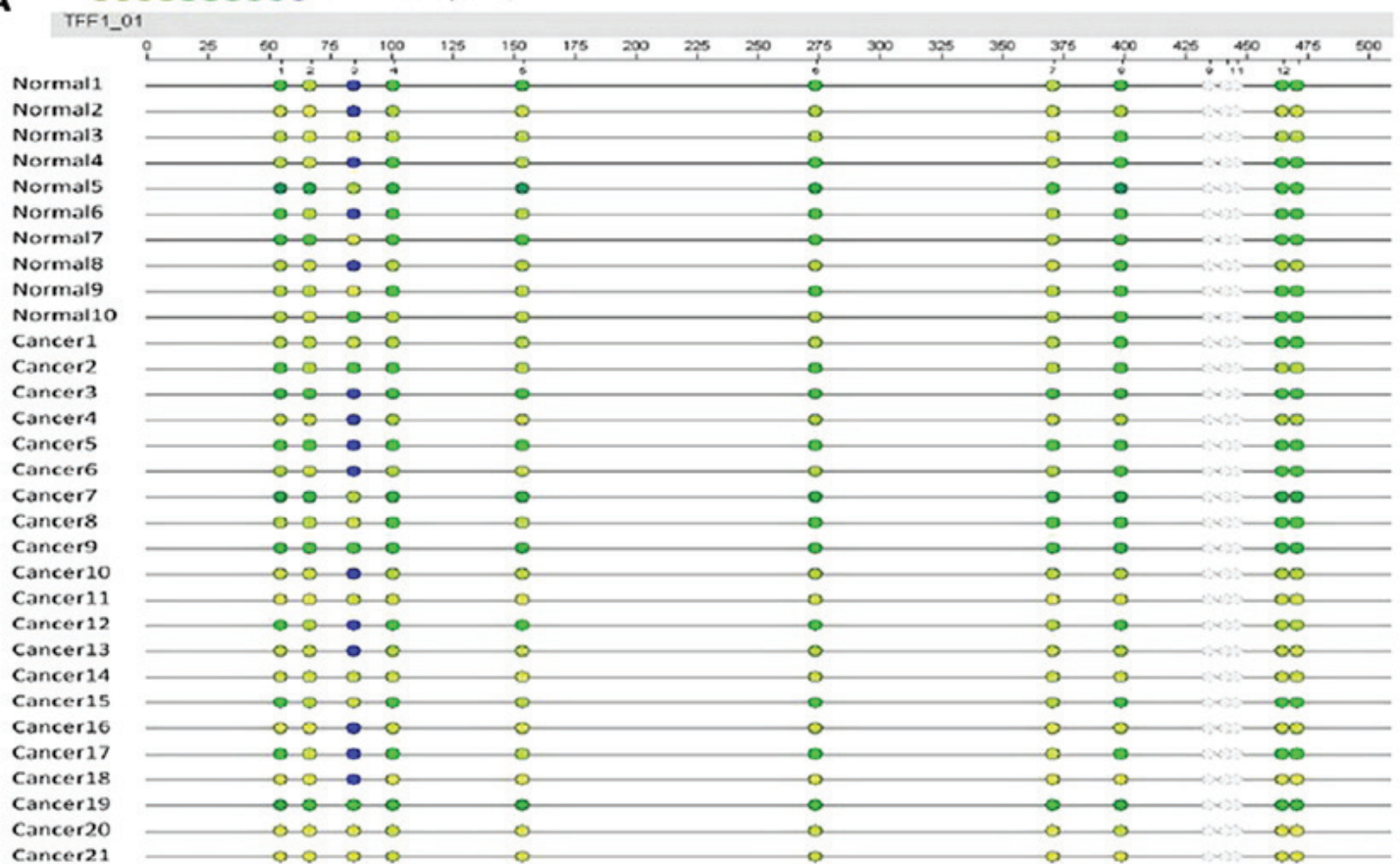

B $0 \% 0000000000100 \%$ Not analyzed

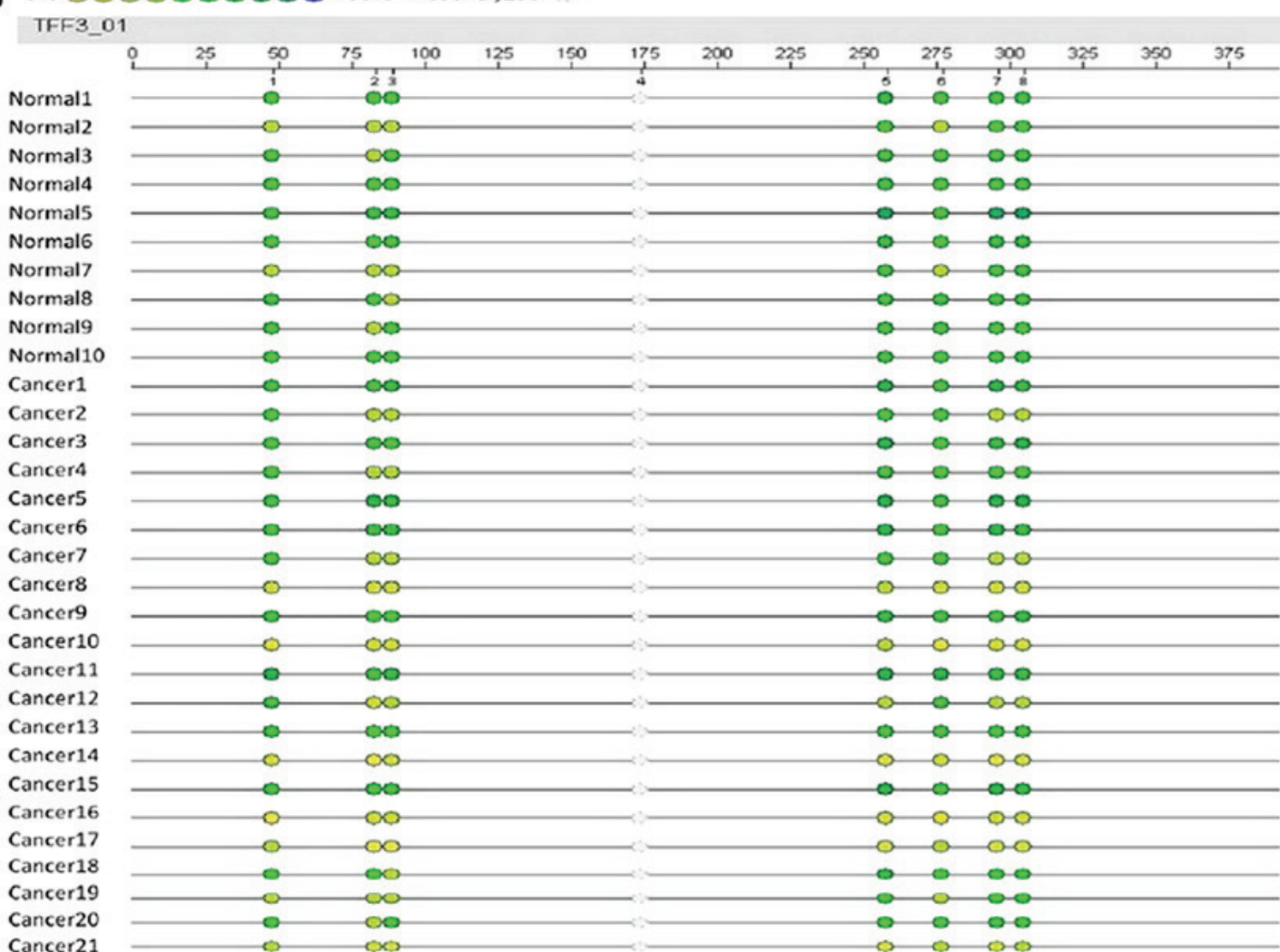

Figure 2. Promoter methylation sites and levels of the TFF1 and TFF3 genes in cancer and normal tissues. (A) The length of promoter region of the TFF1 gene for detection was $489 \mathrm{bp}, 13$ units of $\mathrm{CpG}$ sites could be found and 10 units were measured successfully. (B) The length of $372 \mathrm{bp}$ was detected for the TFF3 gene and 7 out of 8 units were analyzed favorably. The different colors represent the relative methylation changes in 10\% increments (yellow, $0 \%$; blue, $100 \%$ methylated). TFF, trefoil factor.

Promoter methylation level of TFF1 and TFF3 and respective gene expression. To evaluate the potential association between the level of promoter methylation and respective gene expression, the promoter methylation patterns of TFF1 and TFF3 in 21 CRC samples and 10 adjacent normal samples were evaluated using MALDI-TOF-MS. A total of $527 \mathrm{CpG}$ sites were observed and 465 sites (88.2\%) were analyzed. A total of 10 promoter region units of TFF1 and 7 units of TFF3 were successfully detected (Fig. 2). The average methylation levels of the TFF1 or TFF3 promoter region in the CRC group were 
Table V. Comparison of average methylation levels in different CPG sites of TFF1 between normal and cancer groups.

\begin{tabular}{lccr}
\hline & \multicolumn{2}{c}{ Average methylation levels (means \pm SD) } & P-value \\
\cline { 2 - 3 } CpG & Colorectal cancer & Normal & 0.416 \\
\hline TFF1_01_CpG_1 & $0.368 \pm 0.179$ & $0.422 \pm 0.164$ & 0.564 \\
TFF1_01_CpG_2 & $0.312 \pm 0.156$ & $0.347 \pm 0.152$ & 0.960 \\
TFF1_01_CpG_3 & $0.637 \pm 0.363$ & $0.644 \pm 0.386$ & 0.312 \\
TFF1_01_CpG_4 & $0.392 \pm 0.130$ & $0.436 \pm 0.099$ & 0.377 \\
TFF1_01_CpG_5 & $0.350 \pm 0.177$ & $0.410 \pm 0.168$ & 0.312 \\
TFF1_01_CpG_6 & $0.392 \pm 0.130$ & $0.436 \pm 0.099$ & 0.642 \\
TFF1_01_CpG_7 & $0.333 \pm 0.141$ & $0.350 \pm 0.063$ & 0.228 \\
TFF1_01_CpG_8 & $0.432 \pm 0.170$ & $0.501 \pm 0.132$ & 0.506 \\
TFF1_01_CpG_12.13 & $0.394 \pm 0.163$ & $0.421 \pm 0.061$ & \\
\hline
\end{tabular}

$\mathrm{P}<0.05$ was considered to indicate a statistically significant difference (Mann Whitney U test). TFF, trefoil factor.

Table VI. Comparison of average methylation levels in different CPG sites of TFF3 between normal and cancer groups.

\begin{tabular}{lccr}
\hline & \multicolumn{2}{c}{ Average methylation levels (means \pm SD) } & Pormal \\
\cline { 2 - 4 } CpG & Colorectal cancer & $0.469 \pm 0.075$ \\
\hline TFF3_01_CpG_1 & $0.435 \pm 0.145$ & $0.432 \pm 0.088$ & 0.394 \\
TFF3_01_CpG_2 & $0.386 \pm 0.161$ & $0.439 \pm 0.088$ & 0.314 \\
TFF3_01_CpG_3 & $0.400 \pm 0.151$ & NA & 0.379 \\
TFF3_01_CpG_4 & NA & $0.469 \pm 0.075$ & NA \\
TFF3_01_CpG_6 & $0.435 \pm 0.145$ & $0.571 \pm 0.101$ & 0.394 \\
TFF3_01_CpG_7 & $0.471 \pm 0.188$ & $0.571 \pm 0.097$ & 0.066 \\
TFF3_01_CpG_8 & $0.474 \pm 0.181$ & 0.062 \\
\hline
\end{tabular}

$\mathrm{P}<0.05$ was considered to indicate a statistically significant difference (Mann Whitney U test). TFF, trefoil factor. NA, not assessed.

Table VII. Comparison of average methylation level of TFF1 and TFF3 between normal and cancer groups.

\begin{tabular}{lccr}
\hline & \multicolumn{2}{c}{ Average methylation levels (means \pm SD) } & Pormal \\
\cline { 2 - 3 } CpG & Colorectal cancer & $0.441 \pm 0.097$ & 0.374 \\
\hline TFF1_01 & $0.401 \pm 0.143$ & $0.508 \pm 0.082$ & 0.145 \\
\hline TFF3_01 & $0.444 \pm 0.157$ & 0 . \\
\hline
\end{tabular}

$\mathrm{P}<0.05$ was considered to indicate a statistically significant difference (Mann Whitney U test. TFF, trefoil factor.

observed to be lower than those in normal group, although these differences were not statistically significantly $(\mathrm{P}=0.374$ and $\mathrm{P}=0.145$, respectively; Table VII). The methylation levels of each promoter unit of TFF1 or TFF3 did not markedly differ between the CRC group and normal group (Tables $\mathrm{V}$ and VI). Two-way hierarchical cluster analysis also revealed that less-dominant clustering was found in the cancer or normal tissues. The hierarchical cluster algorithm could not separate the colon cancer samples from the normal tissue samples (Fig. 3). In addition, following correlation analysis, no correlation was observed between the promoter methylation and expression of TFF1 or TFF3 (Tables VIII and IX, and Fig. 4).

TFF3 enhances the proliferation, migration and invasion of CCCs. TFF3 expression in 3 human CCC lines (HT29, SW620 and LoVo) and an immortalized human epithelial cell line (HIEC) was examined by both RT-qPCR and western blot analysis. As illustrated in Fig. 5A, TFF3 expression in the HT29 cells was the lowest among the 4 cell lines, while the 
Table VIII. Correlation between the methylation level and mRNA expression of TFF3.

\begin{tabular}{lcccc}
\hline Continuous variable & No. & Means \pm SD & Pearson's correlation & P-value \\
\hline TFF3 methylation level & 21 & $0.441 \pm 0.097$ & 0.231 & 0.315 \\
TFF3 mRNA & 21 & $2.612 \pm 1.631$ & & \\
\hline
\end{tabular}

$\mathrm{P}<0.05$ was considered to indicate a statistically significant difference (Pearson's correlation). TFF, trefoil factor.

Table IX. Correlation between methylation level and mRNA expression for TFF1.

\begin{tabular}{lccc}
\hline Continuous variable & No. & Means \pm SD & Pearson's correlation \\
\hline TFF1 methylation level & 21 & $0.441 \pm 0.097$ & 0.126 \\
TFF1 mRNA & 21 & $2.101 \pm 1.802$ & 0.587 \\
\hline
\end{tabular}

$\mathrm{P}<0.05$ was considered to indicate a statistically significant difference (Pearson's correlation). TFF, trefoil factor.

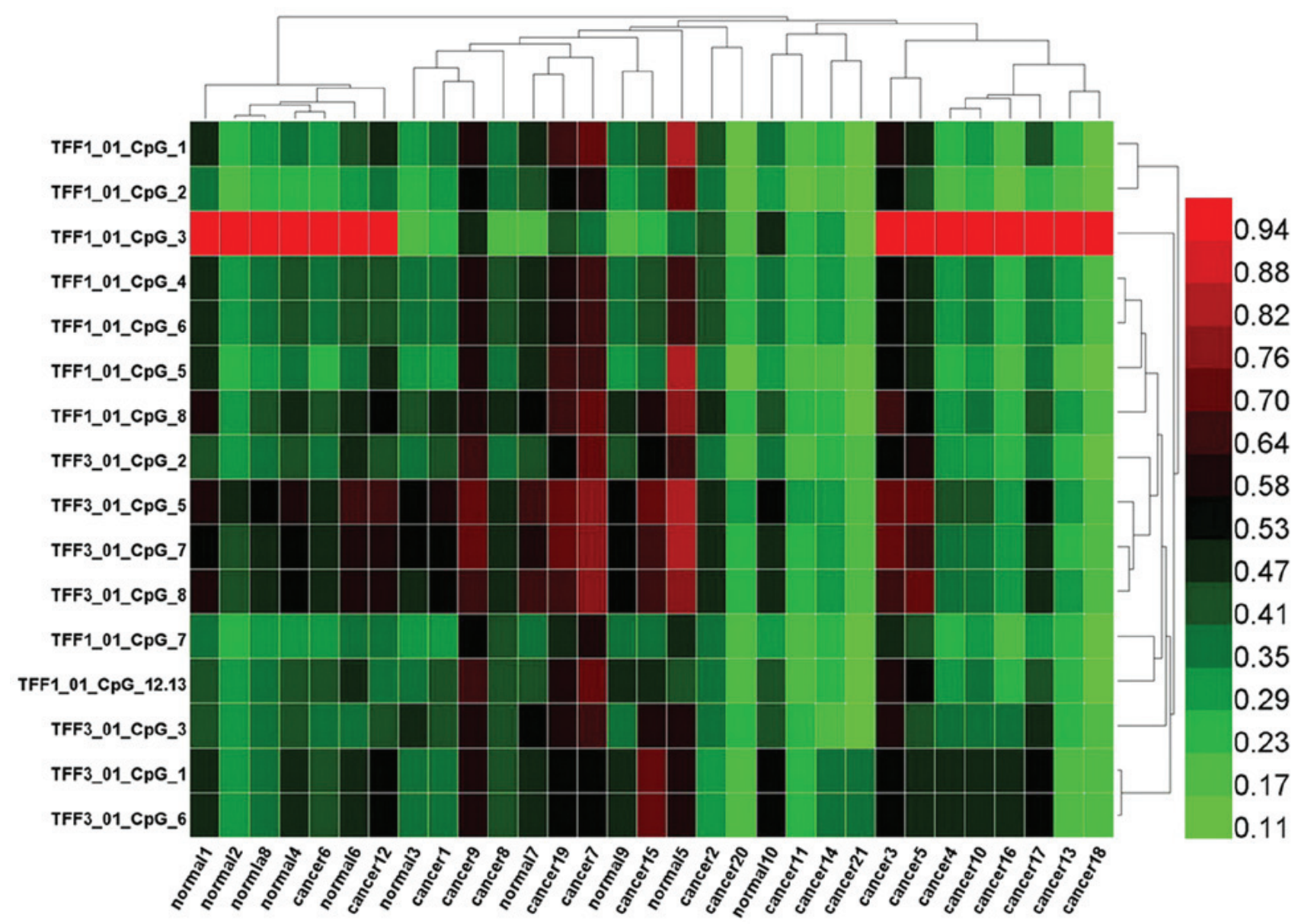

Figure 3. Two-way hierarchical cluster analysis of 21 cancer tissue and 10 normal tissue samples (columns) and DNA-methylation of CpG Units in promoter regions (rows). DNA-methylation levels are depicted in this heatmap on a continuous scale from light green (unmethylated) to light red (100\% methylated). Poor quality data is shown in black. Less-dominant clustering was found in cancer or normal tissues. The hierarchical cluster algorithm could not separate colon cancer samples from normal tissue samples.

highest expression of TFF3 was observed in the LoVo cells. Both RT-qPCR and western blot analysis demonstrated that transfection with a TFF3 expression plasmid resulted in an enhanced expression of TFF3 in the HT29 cells (Fig. 5B). The Cell Counting kit-8 (CCK-8) assay revealed an apparently higher proliferation in the pIRES2-TFF3-transfected cells than 

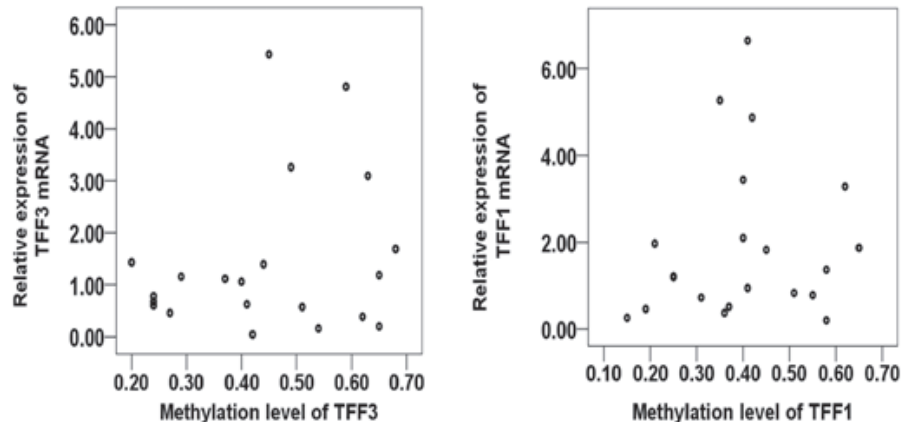

Figure 4. Correlation analysis between the promoter methylation level and mRNA expression of TFF1 or TFF3. No apparent variation trends were observed from the scatter diagrams for TFF1 or TFF3. TFF, trefoil factor.

A
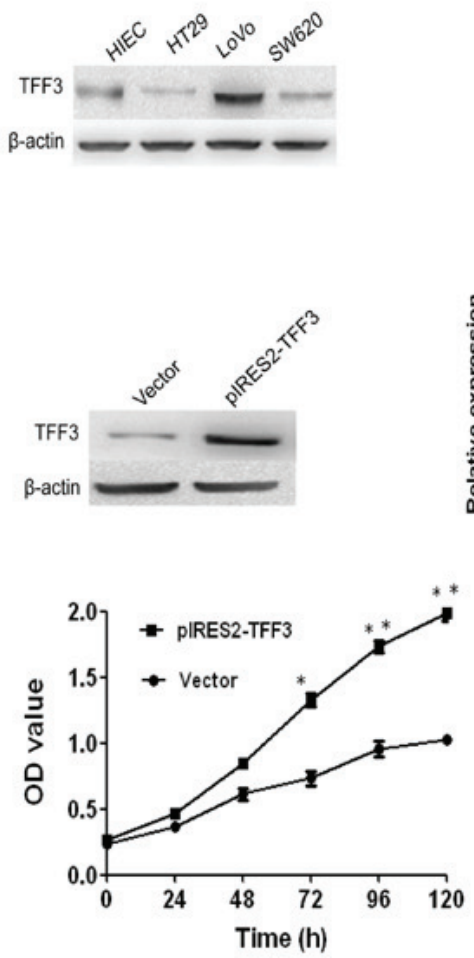

D
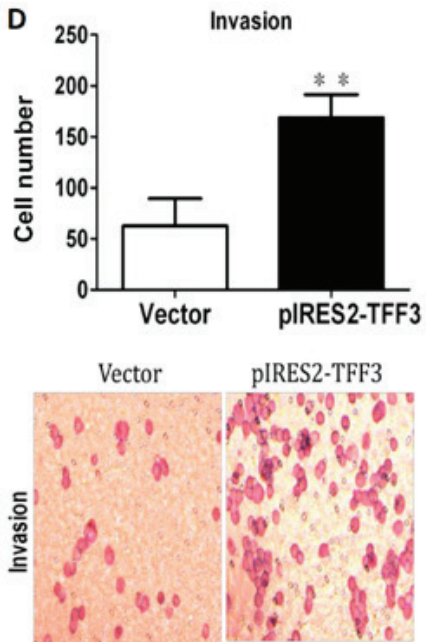
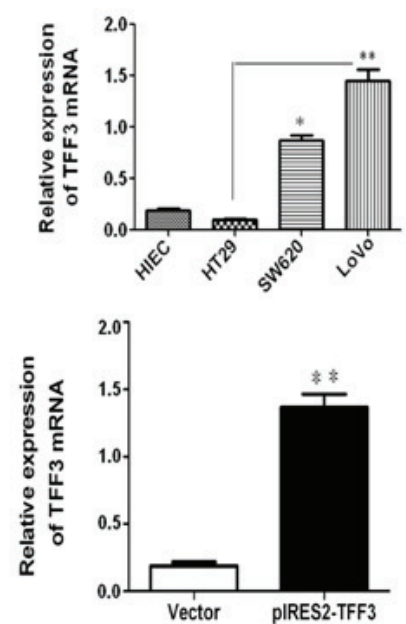

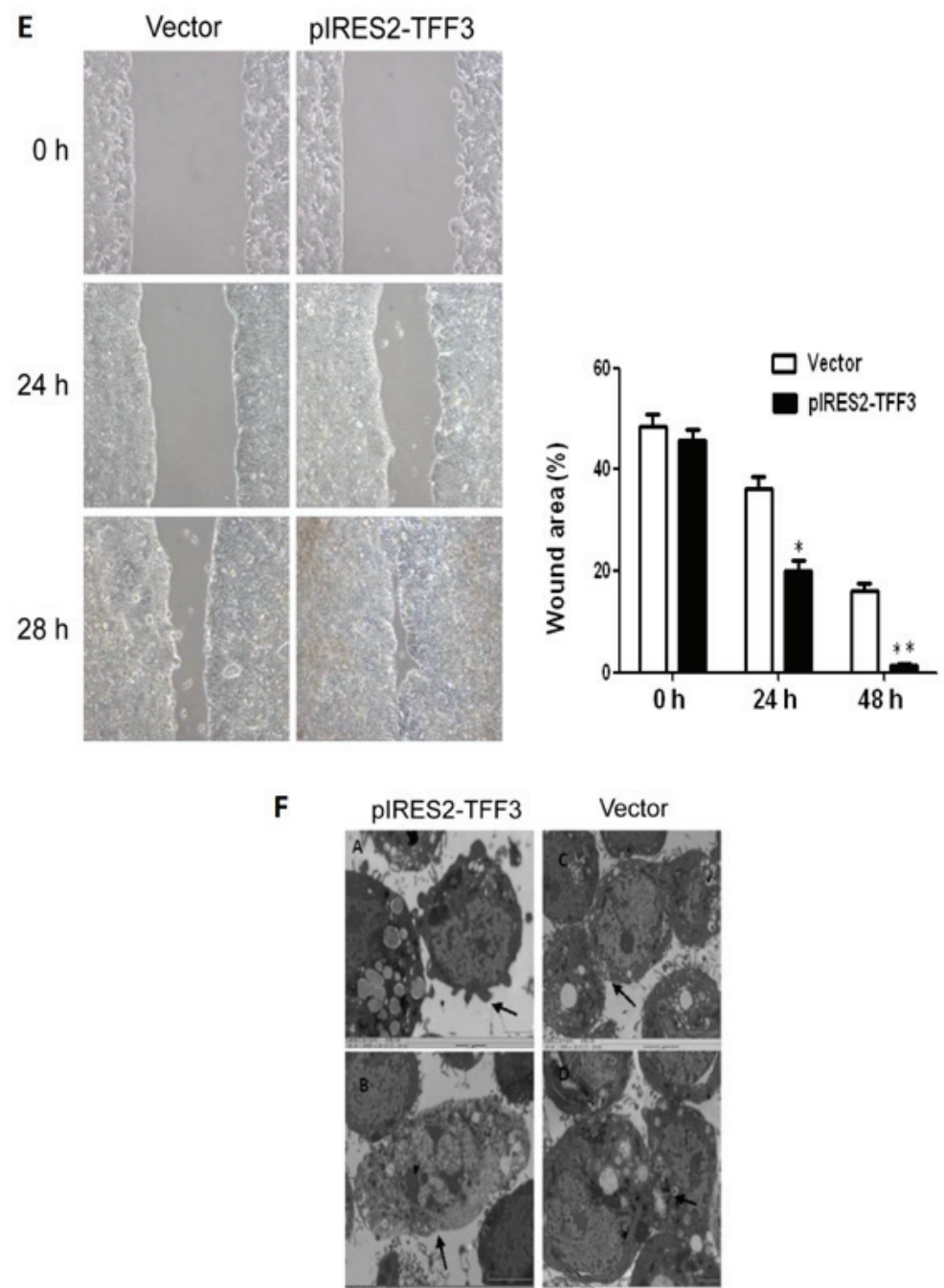

Figure 5. Continued. (E) The migration of the HT29 cells was also markedly increased according to wound healing assay. (F) Compared with the control group, the pIRES2-TFF3-transfected cells exhibited less pseudopodia (A), a reduced number of villi (B) and fewer intercellular junctions (C and D). An increased number of polygonal or spindle-like shaped cells in the TFF3 overexpression group was also observed (B). ${ }^{*} \mathrm{P}<0.05$ and ${ }^{* *} \mathrm{P}<0.01$ vs. control (HIEC) group or the empty vector (Vector). TFF, trefoil factor.

in the empty vector-transfected controls (Fig. 5C). An elevated expression of TFF3 was also found to have increased the invasive and migratory ability of the pIRES2-TFF3-transfected cells (Fig. 5D). Furthermore, wound healing assay revealed that the pIRES2-TFF3-transfected cells migrated at a more rapid rate (as shown by the wound closure speed) than the empty vector-transfected cells (Fig. 5E). Lastly, compared with the control group, the pIRES2-TFF3-transfected cells exhibited fewer intercellular junctions and a reduced number of villi and less pseudopodia. An increased number of polygonal or spindle cells in the TFF3 overexpression group was also observed (Fig. 5F).

Downregulation of TFF3 inhibits CCC proliferation, migration and invasion. TFF3 was silenced in the LoVo cells, which expressed the highest levels of TFF3, via shRNA transfection in order to further assess the effects of TFF3 on cancer progression. As shown in Fig. 6A, both RT-qPCR and western blot analysis revealed that TFF3 expression was markedly reduced following transfection with the shRNA sequences. The downregulation of TFF3 notably reduced the proliferation of the LoVo cells, as indicated by the results of CCK-8 assay (Fig. 6B). The invasive and migratory abilities of the LoVo cells were also found to be markedly reduced following the knockdown of TFF3, as shown by the Transwell assay results (Fig. 6C). Lastly, the wound healing assay also demonstrated that the migratory capacity of the LoVo cells was impaired by the silencing of TFF3 (Fig. 6D).

TFF3 accelerates the EMT process of CCCs. The expression of EMT markers was examined by both western blot analysis and RT-qPCR to confirm whether TFF3 promotes cancer progression through EMT. As illustrated in Fig. 7A and C, the elevated expression of TFF3 in the HT29 cells resulted in the downregulation of E-cadherin, a well-established epithelial marker, at both the protein and mRNA level. TFF3 expression also promoted an increase in the mRNA and protein levels of the mesenchymal markers, Twist1, Snail and Vimentin. Furthermore, the shRNA-mediated knockdown of TFF3 upregulated E-cadherin expression, and suppressed the expression of Twist1, Snail and Vimentin in the LoVo cells at both the protein and mRNA level (Fig. 7B and C). 
A
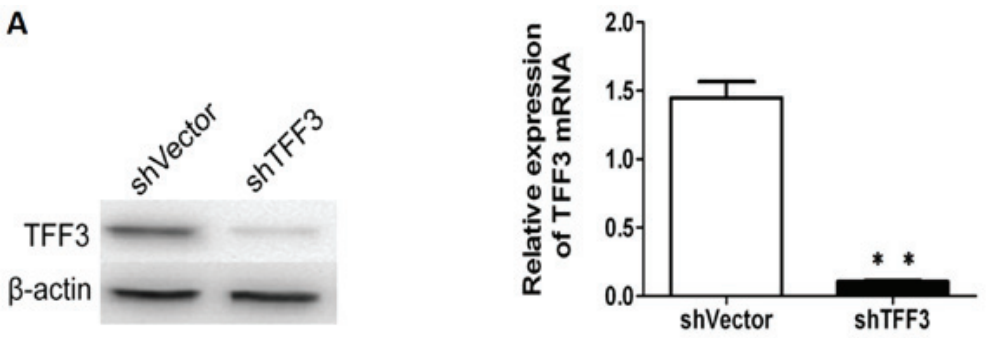

B
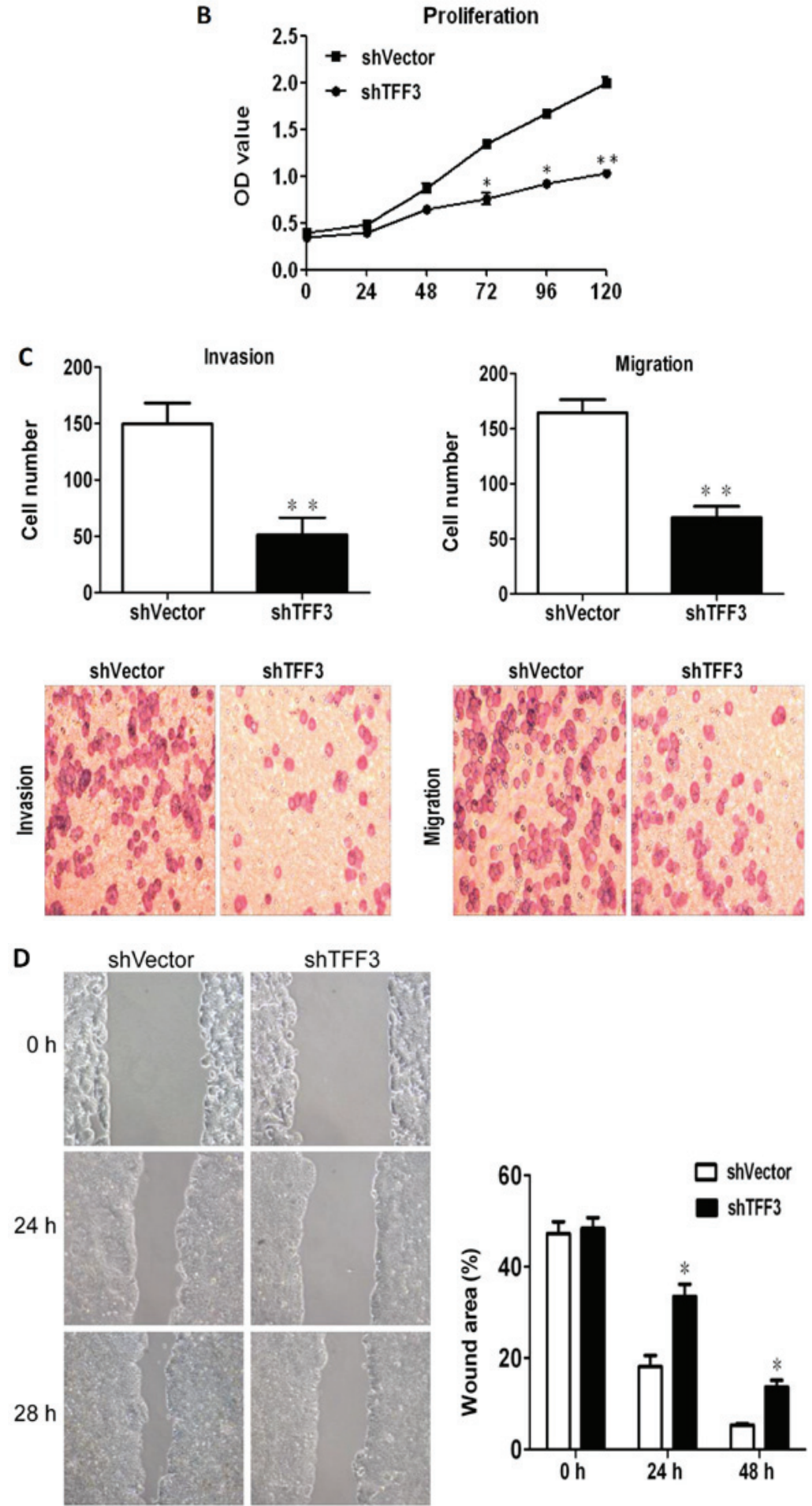

Figure 6. Knockdown of TFF3 notably reduces the proliferation, migration and invasion of LoVo cells. (A) TFF3 expression was suppressed by shRNA transfection, as shown by both western blot analysis and RT-qPCR. (B) CCK-8 assay revealed that the silencing of TFF3 significantly decreased the proliferation of the LoVo cells. (C) The migration and invasion of Lovo cells were markedly suppressed following the silencing of TFF3, as shown by Transwell chamber assay. (D) Scratch wound healing assay demonstrated that the migration of the LoVo cells was markedly reduced by the silencing of TFF3. ${ }^{*} \mathrm{P}<0.05$ and ${ }^{* *} \mathrm{P}<0.01 \mathrm{vs}$. shvector. TFF, trefoil factor. 
A

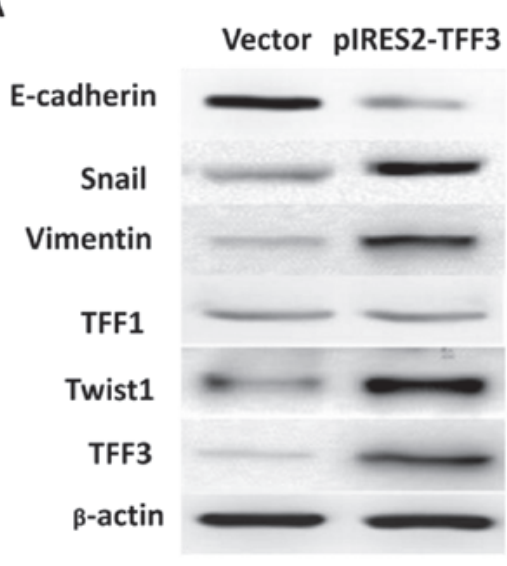

B
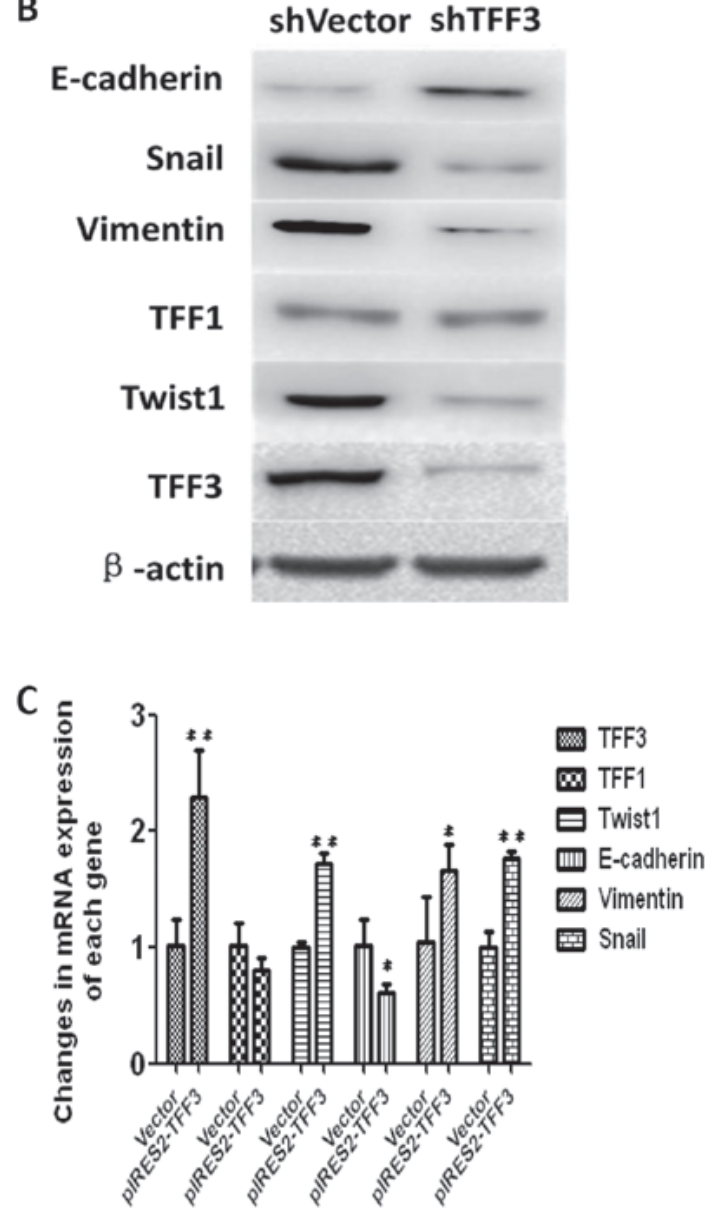

D

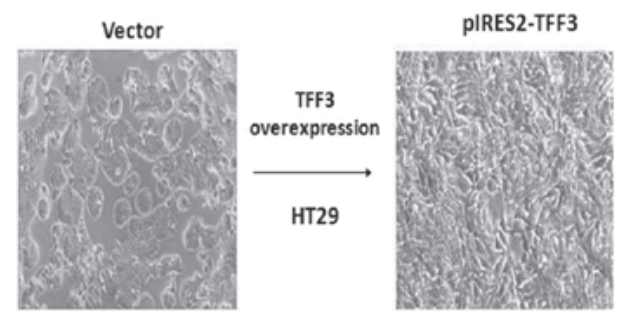

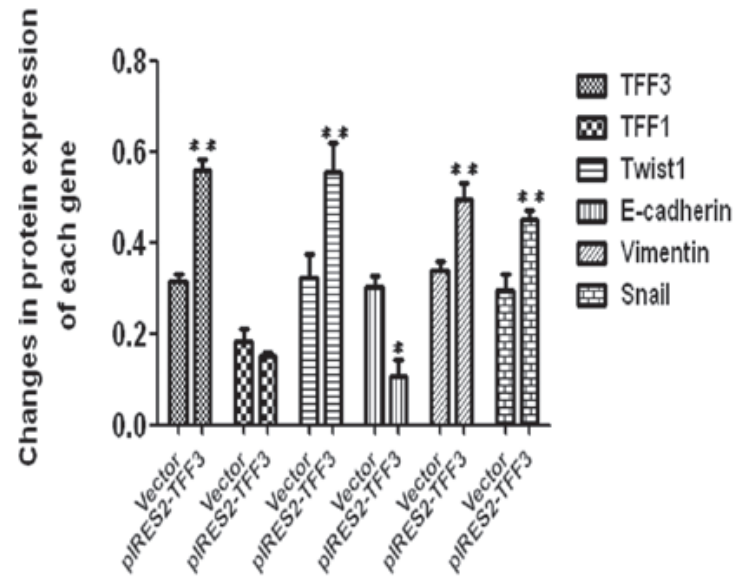
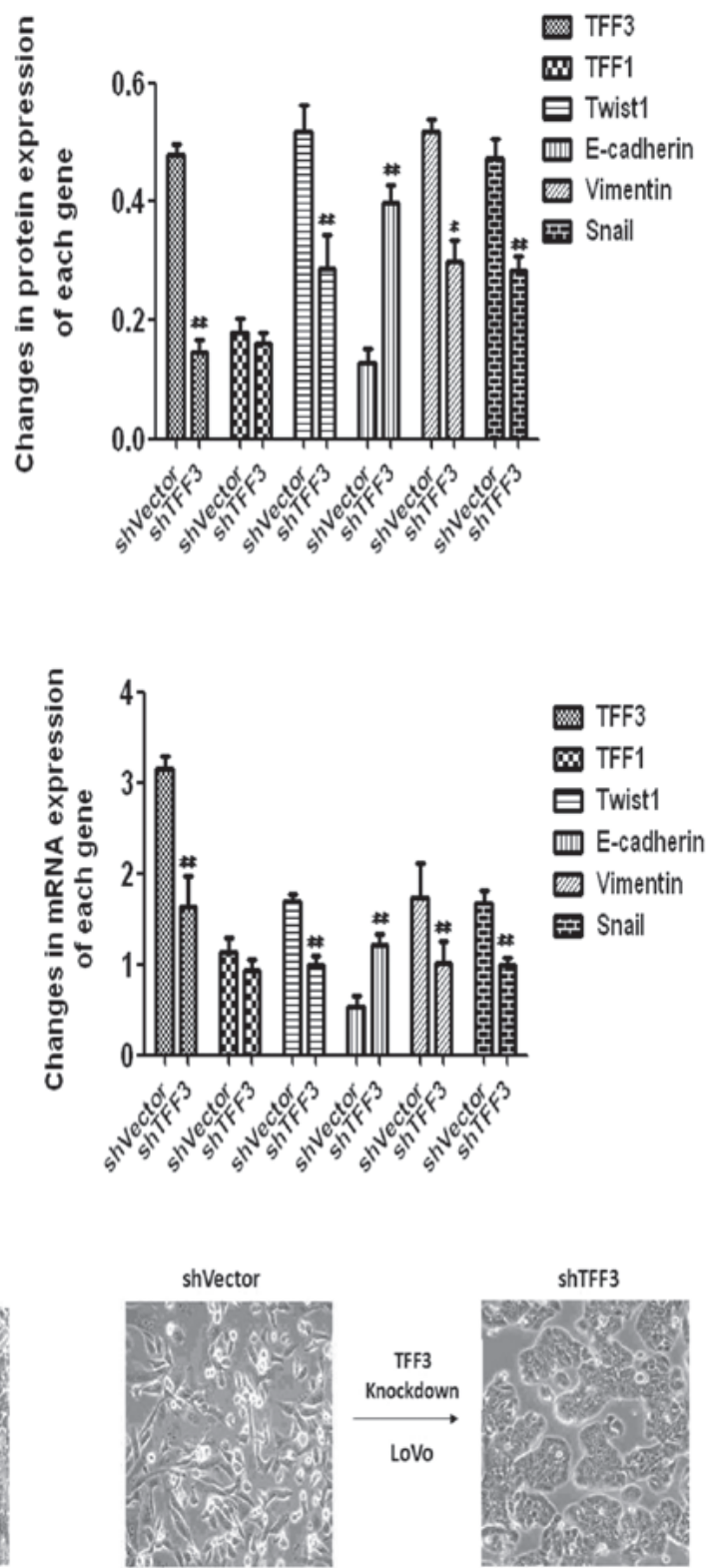

Figure 7. TFF3 induces the EMT process in colorectal cancer cells. (A) Western blot analysis demonstrated that the enforced expression of TFF3 in HT29 cells increased the protein expression of Twist1, Snail and Vimentin, while it suppressed E-cadherin expression. (B) The downregulation of TFF3 expression in the Lovo cells decreased the protein expression of Twist1, Snail and Vimentin, while it enhanced E-cadherin expression. (C) The same results were observed at the mRNA level when TFF3 was overexpressed or silenced. (D) EMT-like morphological changes in cells following the overexpression or silencing of TFF3. The morphology of the HT29 cells changed from a round or volmer-weber mode into a triangular or spindle form following the overexpression of TFF3. LoVo cells displayed a reversed morphological change from the scattered cord-like form to the round, rectangular or clustered pattern after the silencing of TFF3. ${ }^{\#} \mathrm{P}<0.05$ and ${ }^{\# \#} \mathrm{P}<0.01$ vs. empty vector (Vector) or shVector. TFF, trefoil factor. 
The EMT-like morphological changes in the cells were also observed under an optical microscope. The shape of the HT29 cells changed from a round or volmer-weber mode into a triangular or spindle form following the overexpression of TFF3. LoVo cells displayed a reversed morphological changes from the scattered cord-like forms to the round, rectangular or clustered patterns following the silencing of TFF3 (Fig.7D).

\section{Discussion}

Studies have indicated that TFF expression may produce undesirable outcomes if overexpressed in tumor tissues, although these proteins have a number of beneficial cytoprotective effects. As a secreted protein, the serum or tissue levels of TFF3 or both TFF1 and TFF3 have been reported to be biomarkers for several malignancies (30-37). Huang et al (38) reported that TFF3 mRNA expression was upregulated in CRC, although not significantly, when compared with paired normal colonic mucosa. TFF3 mRNA is also elevated in CRCs with lymph node metastasis when compared with that of non-metastatic cancer. Our previous study observed higher protein levels of TFF1 and decreased levels of TFF3 in cancer tissue than in adjacent normal tissue via immunohistochemistry, and revealed that a higher expression of TFF3 was associated with lymph node metastasis, TNM stage and a poor prognosis (39). In the present study, a higher number of samples were used to confirm the mRNA expression levels of both TFF1 and TFF3 and verify previous results. The results of the present study confirmed the elevated expression levels of both TFF1 and 3 in neoplastic tissues compared with adjacent normal tissues. Moreover, a higher TFF1 mRNA expression was associated with metastasis prior to treatment, TNM staging and CRM, but was not associated with survival. On the other hand, a higher expression of TFF3 was associated with histological type, invasion depth, lymph node number, metastasis prior to treatment, TNM staging, recurrence or metastasis after surgery and poor survival, indicating that higher expression of TFF3 is predominantly associated with cancer malignancy. Thus, TFF3 expression in CRC tissues may be a novel prognostic factor.

Changes in DNA methylation of certain tumor suppressor genes and consecutive changes in mRNA expression are one of the earliest events in the development of CRC, often occurring prior to the appearance of mutations in well-known genes, including the adenomatous polyposis coli gene (40-42). TFF3 overexpression associated with specific promoter $\mathrm{CpG}$ hypomethylation has been identified in mouse and human hepatocellular carcinoma tissues, and promoter $\mathrm{CpG}$ hypomethylation of TFF3 has been posited to be a potential mechanism of TFF3 overexpression in hepatocellular cancer (43). Vestergaard et al (44) reported the hypomethylation of TFF1 and TFF3 promoter regions in prostate cancer (PC) cell lines, with significantly increased TFF expression compared with both benign immortalized prostate cell lines and PC cell lines not expressing TFF. In clinical samples, methylation of the TFF1 and TFF3 promoter regions has been observed to be significantly lower in PC samples compared with benign prostatic hyperplastic samples. Moreover, the hypomethylation of $\mathrm{CpG}$ sites has also been reported in mouse small intestine tissue overexpressing TFF3 (45) and in human pancreatic ductal carcinomas (46). Based on these data, the present study also evaluated the levels of promoter methylation of TFF1 and TFF3 in CRC samples in order to determine whether their expression levels at the transcriptional level are regulated by their promoter methylation patterns. The results revealed that there was no apparent difference in methylation levels between neoplastic and normal tissue. In addition, no correlation between methylation level and mRNA expression of TFF1 or TFF3 in CRC samples was observed ( $P>0.05)$, which may indicate that the mRNA expression of the two genes in CRC tissues is not determined by promoter methylation. However, this may have been influenced by the insufficient number of samples, and further research is required to confirm these results.

Although TFF3 is associated with malignancy in a number of types of cancer, its underlying signaling pathway is not yet well understood. TFF3 may promote the development of malignant tumors by acting both directly on malignant cells and indirectly on the vasculature (29). TFF3 has also been reported to participate in the metastasis of breast cancer through the repression of cadherin 1 via STAT3 (19). TFF3 was also first associated with Twist-mediated cell migration in gastric cancer cells (47). However, controversial reports have emerged, raising doubts regarding the exact role of TFF3 in cancer progression. Uchino et al (48) reported that TFF3 inhibited the growth of CRC cells. It was also shown that TFF3 overexpression markedly decreased the proliferation of the SW837 and LoVo CCC lines (49). TFF3 has also been reported to promote the migration and invasiveness of rat fibroblasts (50), the migration of gastric mucosal epithelial cells (51), and the proliferation, viability and survival of breast cancer (17) and prostate carcinoma cells $(52,53)$.

The present study performed a number of functional tests on the role of TFF3 to explore its involvement in colon cancer progression. The results revealed that the overexpression of TFF3 intensified proliferation, migration and invasion capacities of HT29 cells, and induced an increase in Twist1, Snail Vimentin levels while causing a decrease in the levels of E-cadherin expressions at both the protein and mRNA levels, indicating that cells were potentially undergoing EMT. On the contrary, the knockdown of TFF3 resulted in opposite effects in the LoVo cells. Moreover, the EMT-like morphological changes in cells were observed following the overexpression or silencing of TFF3. The HT29 cells lost the epithelial forms gradually and obtained mesenchymal patterns following the overexpression of TFF3, while the LoVo cells demonstrated a reversed morphological changes after the silencing of TFF3. Therefore, these results suggest that TFF3 may promote colon cancer progression via EMT.

In conclusion, the results of the present study suggest that TFF3 may be a novel biomarker for survival estimates of patients with colon cancer, and may promote the malignant progression of CCCs by activating the EMT process. In addition, the present study also provided preclinical proof that TFF3 may be a potential target for the treatment of CRC.

\section{Acknowledgements}

Not applicable. 


\section{Funding}

This study was supported by the Natural Science Fund of the Xin Jiang Uyghur Autonomous Region (grant no. 2019D01C253).

\section{Availability of data and materials}

All data generated or analyzed during this study are included in this published article or are available from the corresponding author on reasonable request.

\section{Authors' contributions}

AY and HW conceived and designed the study. AY wrote the first draft of the manuscript. PS and RT assisted with the collection of the clinicopathological materials and the overall statistics and analysis of the data. CF and FW assisted in performing experiments, such as transfection, proliferation, invasion, migration, RT-qPCR and western blot analysis. All authors have read and approved the final manuscript.

\section{Ethics approval and consent to participate}

This study was approved by the Ethics Committee of the Tumor Hospital of Xin Jiang Medical University (approval no. 20110110, 10 January, 2011) and all procedures followed the principles of the Declaration of Helsinki. All subjects provided written informed consent prior to participation.

\section{Patient consent for publication}

Not applicable.

\section{Competing interests}

The authors declare that they have no competing interests

\section{References}

1. Cai SJ and Peng JJ: Colorectal cancer epidemiology and prevention strategies. In: Proc Academic Annual Conference of CSCO2014,294-301, Peking, China, 2014.

2. Li S, Wang J, Lu Y and Fan D: Screening and early diagnosis of colorectal cancer in China: A 12 year retrospect (1994-2006). J Cancer Res Clin Oncol 133: 679-686, 2007.

3. Gespach C: Trefoil factors. In: Encyclopedia of Cancer. Schwab M (ed). Springer.Berlin, Heidelberg, pp4652-4658, 2011

4. Sands BE and Podolsky DK: The trefoil peptide family. Annu Rev Physiol 58: 253-273, 1996.

5. Wright NA, Poulsom R, Stamp G, Van Noorden S, Sarraf C, Elia G, Ahnen D, Jeffery R, Longcroft J, Pike C, et al: Trefoil peptide gene expression in gastrointestinal epithelial cells in inflammatory bowel disease. Gastroenterology 104: 12-20, 1993

6. Regalo G, Wright NA and Machado JC: Trefoil factors: From ulceration to neoplasia. Cell Mol Life Sci 62: 2910-2915, 2005.

7. Hernández C, Santamatilde E, McCreath KJ, Cervera AM, Díez I, Ortiz-Masiá D, Martínez N, Calatayud S, Esplugues JV and Barrachina MD: Induction of trefoil factor (TFF)1, TFF2 and TFF3 by hypoxia is mediated by hypoxia inducible factor-1: Implications for gastric mucosal healing. Br J Pharmacol 156: 262-272, 2009

8. Taupin D and Podolsky DK: Trefoil factors: Initiators of mucosal healing. Nat Rev Mol Cell Biol 4: 721-732, 2003.

9. May FE and Westley BR: Trefoil proteins: Their role in normal and malignant cells. J Pathol 183: 4-7, 1997.
10. Prest SJ, May FE and Westley BR: The estrogen-regulated protein, TFF1, stimulates migration of human breast cancer cells. FASEB J 16: 592-594, 2002.

11. Machado JC, Nogueira AM, Carneiro F, Reis CA and Sobrinho-Simões M: Gastric carcinoma exhibits distinct types of cell differentiation: An immunohistochemical study of trefoil peptides (TFF1 and TFF2) and mucins (MUC1, MUC2, MUC5AC, and MUC6). J Pathol 190: 437-443, 2000.

12. Dhar DK, Wang TC, Tabara H, Tonomoto Y, Maruyama R, Tachibana M, Kubota $\mathrm{H}$ and Nagasue N: Expression of trefoil factor family members correlates with patient prognosis and neoangiogenesis. Clin Cancer Res 11: 6472-6478, 2005.

13. Madsen J, Nielsen O, Tornøe I, Thim L and Holmskov U: Tissue localization of human trefoil factors 1,2 , and 3. J Histochem Cytochem 55: 505-513, 2007.

14. Rodrigues S, Rodrigue CM, Attoub S, Fléjou JF, Bruyneel E, Bracke M, Emami S and Gespach C: Induction of the adenoma-carcinoma progression and Cdc25A-B phosphatases by the trefoil factor TFF1 in human colon epithelial cells. Oncogene 25: 6628-6636, 2006.

15. Arumugam T, Brandt W, Ramachandran V, Moore TT, Wang H, May FE, Westley BR, Hwang RF and Logsdon CD: Trefoil factor 1 stimulates both pancreatic cancer and stellate cells and increases metastasis. Pancreas 40: 815-822, 2011.

16. Zhao S, Ma Y and Huang X: Trefoil factor 1 elevates the malignant phenotype of mucinous ovarian cancer cell through Wnt $/ \beta$-catenin signaling. Int J Clin Exp Pathol 8: 10412-10419, 2015.

17. Kannan N, Kang J, Kong X, Tang J, Perry JK, Mohankumar KM, Miller LD, Liu ET, Mertani HC, Zhu T, et al: Trefoil factor 3 is oncogenic and mediates anti-estrogen resistance in human mammary carcinoma. Neoplasia 12: 1041-1053, 2010.

18. Gu J, Zheng L, Zhang L, Chen S, Zhu M, Li X and Wang Y: TFF3 and HER2 expression and their correlation with survival in gastric cancer. Tumour Biol 36: 3001-3007, 2015.

19. Pandey V, Wu ZS, Zhang M, Li R, Zhang J, Zhu T and Lobie PE: Trefoil factor 3 promotes metastatic seeding and predicts poor survival outcome of patients with mammary carcinoma. Breast Cancer Res 16: 429-448, 2014.

20. Ishibashi Y, Ohtsu H, Ikemura M, Kikuchi Y, Niwa T, Nishioka K, Uchida Y, Miura H, Aikou S, Gunji T, et al: Serum TFF1 and TFF3 but not TFF2 are higher in women with breast cancer than in women without breast cancer. Sci Rep 7: 4846-4854, 2017.

21. Lacroix M: Significance, detection and markers of disseminated breast cancer cells. Endocr Relat Cancer 13: 1033-1067, 2006.

22. Im S, Yoo C, Jung JH, Choi HJ, Yoo J and Kang CS: Reduced expression of TFF1 and increased expression of TFF3 in gastric cancer: Correlation with clinicopathological parameters and prognosis. Int J Med Sci 10: 133-140, 2013.

23. Vestergaard EM, Borre M, Poulsen SS, Nexø E and Tørring N: Plasma levels of trefoil factors are increased in patients with advanced prostate cancer. Clin Cancer Res 12: 807-812, 2006.

24. Casado E, Garcia VM, Sánchez JJ, Gómez Del Pulgar MT, Feliu J, Maurel J, Castelo B, Moreno Rubio J, López RA, García-Cabezas MÁ, et al: Upregulation of trefoil factor 3 (TFF3) after rectal cancer chemoradiotherapy is an adverse prognostic factor and a potential therapeutic target. Int J Radiat Oncol Biol Phys 84: 1151-1158, 2012.

25. Martin TA, Goyal A, Watkins G and Jiang WG: Expression of the transcription factors snail, slug, and twist and their clinical significance in human breast cancer. Ann Surg Oncol 12: 488-496, 2005.

26. Khan MA, Chen HC, Zhang D and Fu J: Twist: A molecular target in cancer therapeutics. Tumour Biol 34: 2497-2506, 2013.

27. Hu P, Yang J, Hou Y, Zhang H, Zeng Z, Zhao L, Yu T, Tang X, Tu G, Cui X, et al: lncRNA expression signatures of twist-induced epithelial-to-mesenchymal transition in MCF10A cells. Cell Signal 26: 83-93, 2014.

28. Livak KJ and Schmittgen TD: Analysis of relative gene expression data using real-time quantitative PCR and the 2(- $\Delta \Delta$ C(T)) Method. Methods 25: 402-408, 2001.

29. Camp RL, Dolled-Filhart M and Rimm DL: X-tile: A new bio-informatics tool for biomarker assessment and outcome-based cut-point optimization. Clin Cancer Res 10: 7252-7259, 2004.

30. May FE: The potential of trefoil proteins as biomarkers in human cancer. Biomarkers Med 6: 301-304, 2012.

31. Xiao P, Ling H, Lan G, Liu J, Hu H and Yang R: Trefoil factors: gastrointestinal specific proteins associated with gastric cancer. Clin Chim Acta 450: 127-134, 2015. 
32. Qu Y, Yang Y, Ma D and Xiao W: Increased trefoil factor 3 levels in the serum of patients with three major histological subtypes of lung cancer. Oncol Rep 27: 1277-1283, 2012.

33. Meng JR, Tang HZ, Zhou KZ, Shen WH and Guo HY: TFF3 and survivin expressions associate with a lower survival rate in gastric cancer. Clin Exp Med 13: 297-303, 2013.

34. May FE and Westley BR: TFF3 is a valuable predictive biomarker of endocrine response in metastatic breast cancer. Endocr Relat Cancer 22: 465-479, 2015.

35. Elnagdy MH, Farouk O, Seleem AK and Nada HA: TFF1 and TFF3 mRNAs are hgher in blood from breast cancer patients with metastatic disease than those without. J Oncol 2018: 4793498, 2018

36. Terris B, Blaveri E, Crnogorac-Jurcevic T, Jones M, Missiaglia E, Ruszniewski P, Sauvanet A and Lemoine NR: Characterization of gene expression profiles in intraductal papillary-mucinous tumors of the pancreas. Am J Pathol 160: 1745-1754, 2002.

37. Faith DA, Isaacs WB, Morgan JD, Fedor HL, Hicks JL, Mangold LA, Walsh PC, Partin AW, Platz EA, Luo J, et al: Trefoil factor 3 overexpression in prostatic carcinoma: Prognostic importance using tissue microarrays. Prostate 61: 215-227, 2004

38. Huang YG, Li YF, Wang LP and Zhang Y: Aberrant expression of trefoil factor 3 is associated with colorectal carcinoma metastasis. J Cancer Res Ther 9: 376-380, 2013.

39. Yusup A, Huji B, Fang C, Wang F, Dadihan T, Wang HJ and Upur H: Expression of trefoil factors and TWIST1 in colorectal cancer and their correlation with metastatic potential and prognosis. World J Gastroenterol 23: 110-120, 2017.

40. Lao VV and Grady WM: Epigenetics and colorectal cancer. Nat Rev Gastroenterol Hepatol 8: 686-700, 2011.

41. Feinberg AP: The epigenetics of cancer etiology. Semin Cancer Biol 14: 427-432, 2004.

42. Suzuki K, Suzuki I, Leodolter A, Alonso S, Horiuchi S, Yamashita K and Perucho M: Global DNA demethylation in gastrointestinal cancer is age dependent and precedes genomic damage. Cancer Cell 9: 199-207, 2006.

43. Okada H, Kimura MT, Tan D, Fujiwara K, Igarashi J, Makuuchi M, Hui AM, Tsurumaru M and Nagase H: Frequent trefoil factor 3 (TFF3) overexpression and promoter hypomethylation in mouse and human hepatocellular carcinomas. Int J Oncol 26: 369-377, 2005 .

44. Vestergaard EM, Nexø E, Tørring N, Borre M, Ørntoft TF and Sørensen KD: Promoter hypomethylation and upregulation of trefoil factorsin prostate cancer. Int J Cancer 127: 1857-1865, 2010.
45. Ribieras S, Lefèbvre O, Tomasetto C and Rio MC: Mouse Trefoil factor genes: Genomic organization, sequences and methylation analyses. Gene 266: 67-75, 2001

46. Sato N, Maitra A, Fukushima N, van Heek NT, Matsubayashi H, Iacobuzio-Donahue CA, Rosty C and Goggins M: Frequent hypomethylation of multiple genes overexpressed in pancreatic ductal adenocarcinoma. Cancer Res 63: 4158-4166, 2003.

47. Zheng Q, Gao J, Li H, Guo W, Mao Q, Gao E and Zhu YQ: Trefoil factor 3 peptide regulates migration via a Twist-dependent pathway in gastric cell. Biochem Biophys Res Commun 438: 6-12, 2013

48. Uchino H, Kataoka H, Itoh H, Sekiya R, Onitsuka T and Koono M: Roles of intestinal trefoil factor (ITF) in human colorectal cancer: ITF suppresses the growth of colorectal carcinoma cells. Hum Cell 12: 181-188, 1999.

49. Uchino $\mathrm{H}$, Kataoka $\mathrm{H}$, Itoh $\mathrm{H}$, Hamasuna $\mathrm{R}$ and Koono $\mathrm{M}$ : Overexpression of intestinal trefoil factor in human colon carcinoma cells reduces cellular growth in vitro and in vivo. Gastroenterology 118: 60-69, 2000.

50. Chan VY, Chan MW, Leung WK, Leung PS, Sung JJ and Chan FK: Intestinal trefoil factor promotes invasion in non-tumorigenic Rat-2 fibroblast cell. Regul Pept 127: 87-94, 2005.

51. Lin J, Sun Z, Zhang W, Liu H, Shao D, Ren Y, Wen Y, Cao L, Wolfram J, Yang Z, et al: Protective effects of intestinal trefoil factor (ITF) on gastric mucosal epithelium through activation of extracellular signal-regulated kinase 1/2 (ERK1/2). Mol Cell Biochem 404: 263-270, 2015.

52. Perera O, Evans A, Pertziger M, MacDonald C, Chen H, Liu DX, Lobie PE and Perry JK: Trefoil factor 3 (TFF3) enhances the oncogenic characteristics of prostate carcinoma cells and reduces sensitivity to ionising radiation. Cancer Lett 361: 104-111, 2015.

53. Liu J, Kim SY, Shin S, Jung SH, Yim SH, Lee JY, Lee SH and Chung YJ: Overexpression of TFF3 is involved in prostate carcinogenesis via blocking mitochondria-mediated apoptosis. Exp Mol Med 50: 110-117, 2018.

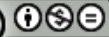

This work is licensed under a Creative Commons Attribution-NonCommercial-NoDerivatives 4.0 International (CC BY-NC-ND 4.0) License. 